\title{
Design and Analysis of Microcontroller-Based, Maximum Power Point Tracker for Photovoltaic Power Systems
}

\author{
Ankit Tamkoria ${ }^{1}$, Neelesh Kumar ${ }^{2}$ \\ ${ }^{1,2}$ DIMAT Raipur, Department of Electrical and Electronics Engineering, Raipur, Pin: 492101, Chhattisgarh, India
}

\begin{abstract}
Maximum power point tracking (MPPT) is used in photovoltaic (PV) systems to maximize the photovoltaic array output power, irrespective of the temperature and irradiation conditions and of the load electrical characteristics. These techniques vary in many aspects as simplicity, digital or analogical implementation, sensor required, convergence speed, and range of effectiveness, implementation hardware, popularity, and cost and in other aspects. A new MPPT system has been developed, consisting of a Buck-type dc/dc converter, which is controlled by a microcontroller-based unit. The main difference between the method used in the proposed MPPT system and other techniques used in the past is that the PV array output power is used to directly control the dc/dc converter, thus reducing the complexity of the system. The resulting system has high-efficiency, lower-cost and can be easily modified to handle more energy sources. This paper describes the development of prototype model based on incremental conductance algorithm in the laboratory, the necessary interface circuits and software control algorithm.
\end{abstract}

Keywords: Photovoltaic (PV) System, Maximum Power Point Tracking (MPPT), Incremental Conductance (IncCond) Technique, Microcontrollers, DC/DC Converter

\section{Introduction}

Maximum photovoltaic power tracking: an algorithm for rapidly changing atmospheric conditions. As the maximum power point (MPP) of photovoltaic (PV) system changes with changing atmospheric conditions (e.g. irradiation and temperature), an important consideration in the design of efficient PV systems is to track the MPP correctly. Many maximum power point tracking (MPPT) techniques have been considered in the past but techniques using microprocessors with appropriate MPPT algorithms are favoured because of their flexibility and compatibility with different PV arrays. Although the efficiency of these MPPT algorithms is usually high, it drops noticeably in cases rapidly changing atmospheric conditions. A new developed MPPT algorithm based on the fact that the MPP of a PV system can be tracked accurately by comparing the incremental and instantaneous conductance of the PV array. The work was carried out by both simulation and experiment; with results showing that the developed incremental conductance (IncCond) algorithm has successfully tracked the MPP, even in cases of rapidly changing atmospheric conditions, and has higher efficiency than ordinary algorithms in terms of total PV energy transferred to the load.

\section{Principle and Technique of MPPT}

A maximum power point (MPPT) is used for extracting the maximum power from the solar panel and transferring maximum power from the PV module to the load. A dc to dc converter which interface between load and module, serve the purpose of transferring maximum power from PV module to the load. By changing the duty cycle the load impedance as seen by the source is varied and matched at the point of the peak power with the source so as to transfer the maximum power. If a battery is just attached to a solar panel, the panel is not running at the maximum power point and the battery could be seriously damaged. What we really need is a circuit that will take power from a changing source and channel that power into a fixed voltage battery. That circuit is a switching mode power supply (SMPS). The power supply can change the load to match the maximum power point by changing the duty cycle of the pulse width modulation (PWM). The PWM can be controlled by the software that determines the MPPT.

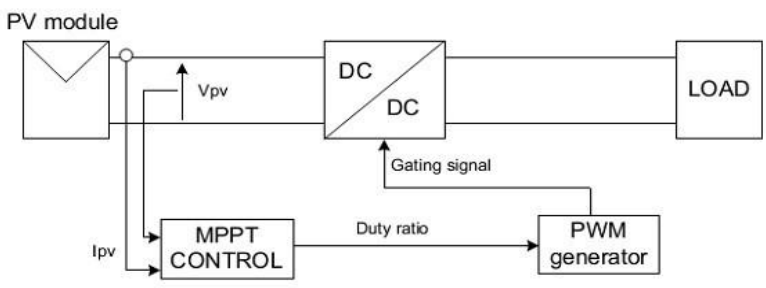

Figure 1: Basic Block of MPPT Controller

By operating a solar panel or array of panels without MPPT controller that can performed maximum power point tracking with lower efficiency or result in wastage of power, and which ultimately require installing more panels for some power requirement. Maximum power point controller is used in PV system to force the PV module operating at its maximum power point (MPP). In this case the PV module produces maximum power output. To overcome the disadvantages of higher initial installation costs and low energy conversion efficiency, MPPT controller used in PV system. The charge controller are connects at the output of solar panels and it compare the panels output to the battery voltage. It then figure out what is the best power that the panel can put out to charge the battery. It takes this and converts it to best voltage to get maximum amps into the battery.

Incremental conductance method w as used for the MPPT tracking of the PV array and hardware is implemented.

Volume 5 Issue 6, June 2016 


\section{International Journal of Science and Research (IJSR) \\ ISSN (Online): 2319-7064}

Index Copernicus Value (2013): 6.14 | Impact Factor (2015): 6.391

The incremental conductance (IncCond) method is based on the fact that the slope of the PV array power curve (Fig. 2) is zero at the MPP, positive on the left of the MPP, and negative on the right, as given by

$\mathrm{dP} / \mathrm{dV}=0$, at MPP

$\mathrm{dP} / \mathrm{dV}>0$, left of MPP

$\mathrm{dP} / \mathrm{dV}<0$, right of MPP

A less obvious, but effective way of performing the IncCond technique is to use the instantaneous conductance and the incremental conductance to generate an error signal

$$
e=\frac{I}{V}+\frac{d I}{d V}
$$

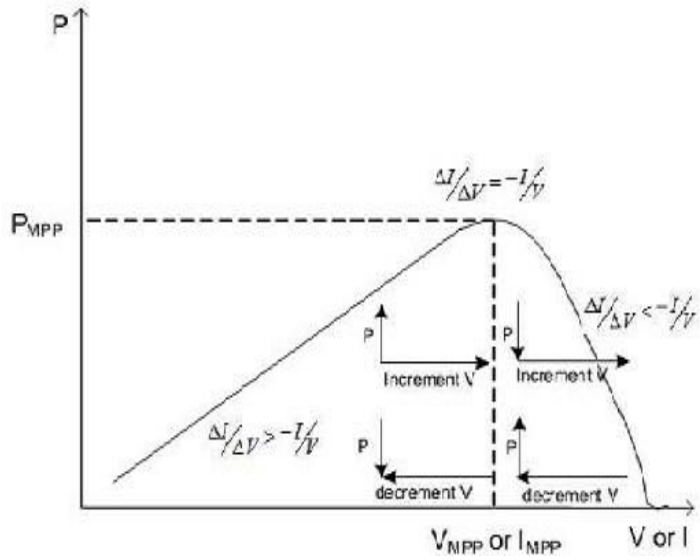

Figure 2: Principle of Incremental Conductance

From (1), we know that $e$ goes to zero at the MPP. A simple proportional integral (PI) control can then be used to drive $e$ to zero. Measurements of the instantaneous PV array voltage and current require two sensors. IncCond method lends itself well to DSP and microcontroller control, which can easily keep track of previous values of voltage and current.

\section{Converter Analysis of PV Application}

Selection of converter depends upon the load specifications and availability of output voltage at PV array. If the load voltage requirement is less and available power is more, we use buck converter, while if load needs more voltage and available is less then we use boost chopper. In our case we are simulating a $36 \mathrm{~W}$ array with Vmpp at $16.56 \mathrm{~V}$ and Impp at $2.25 \mathrm{~A}$ And load is a $30 \mathrm{~V}$ battery requiring a charging current of 1.2 A. Hence we go with a DC-DC boost chopper for meeting our requirements. But before proceeding further we do a comparative analysis of different converter topologies used in MPPT controllers.

\subsection{Buck Converter}

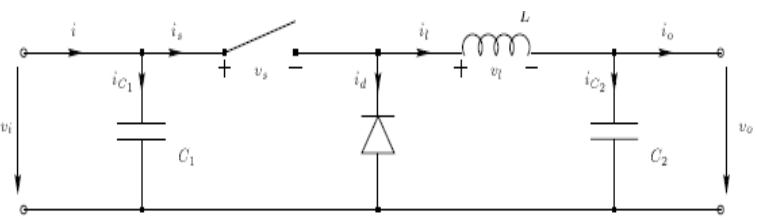

Figure 3: Buck Converter

The conversion ratio is given by the following expression

$$
\frac{V_{o}}{V_{i n}}=\frac{I_{i n}}{I_{o}}=D
$$

Where D is the duty cycle. Knowing Vin and Iin, we can find the input resistance of the converter. This is given by Hence

$$
R_{i n}=\frac{R_{o}}{D^{2}}
$$

Where Ro is the output resistance or load resistance of the converter. We know that $\mathrm{D}$ varies from 0 to $\infty$ ( 0 to 1 not inf). Hence Rin would vary from $\infty$ to Ro as D varies from 0 to 1 correspondingly. The range of Rin values for buck converters as shown in the following figures.

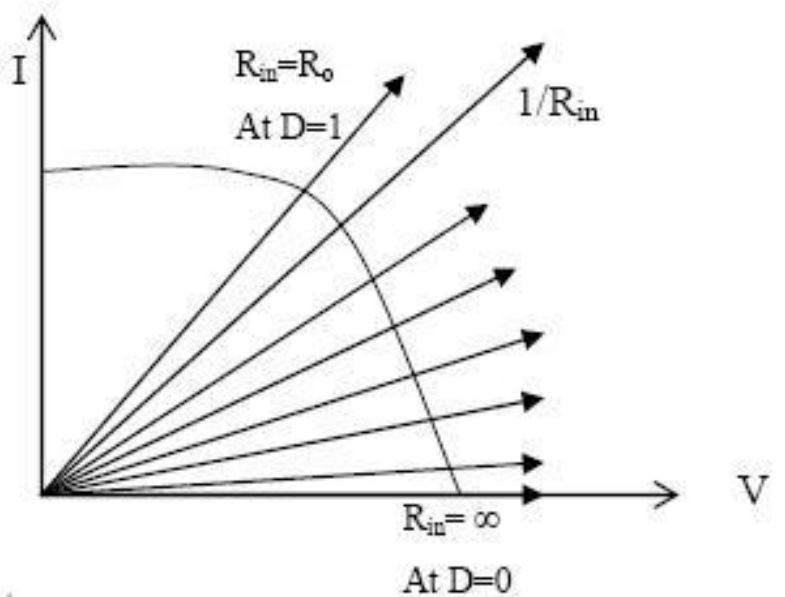

Figure 4: Range of Rin Values for buck converter

\subsection{Boost Converter}

This is a converter whose output voltage is larger than the input voltage and output current is smaller than the input current. The circuit diagram is shown in the following figure.

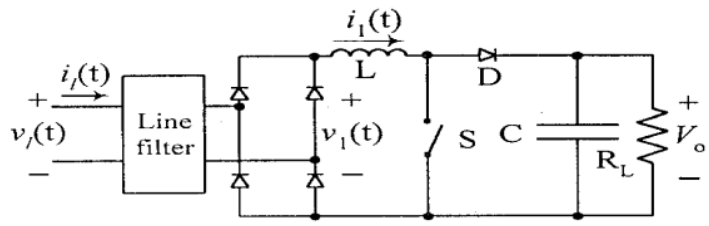

Figure 5: Boost Converter

The conversion ratio is given by the following expression:

$$
\frac{V_{o}}{V_{\text {in }}}=\frac{I_{\text {in }}}{I_{o}}=\frac{1}{1-D}
$$

Where D is the duty cycle. Knowing Vin and Iin, we can find the input resistance of the converter. This is given by

$$
R_{\text {in }}=R_{o}(1-D)^{2}
$$

The maximum power point tracking system will modify the value of Rin, trying to get Rin $=$ Rmpp . However, this will not be possible if Rmpp does not belong to the set of values allowed for Rin, that is, the system will not reach the MPP if $\mathrm{R} 1<\mathrm{Rmpp}$. The behavior is clearly opposite to that mentioned in the previous section, and therefore there is an inversion of zones with respect to the buck converter. Fig 4.7 shows this effect. The impedance at the input of a boost converter is always a lessened version in a factor lower than or equal to 1 of the impedance connected to its output. Therefore, the MPP capture will only be possible for $\mathrm{R} 1 \geq \mathrm{Rmpp}$ values. 


\section{International Journal of Science and Research (IJSR) \\ ISSN (Online): 2319-7064}

Index Copernicus Value (2013): 6.14 | Impact Factor (2015): 6.391

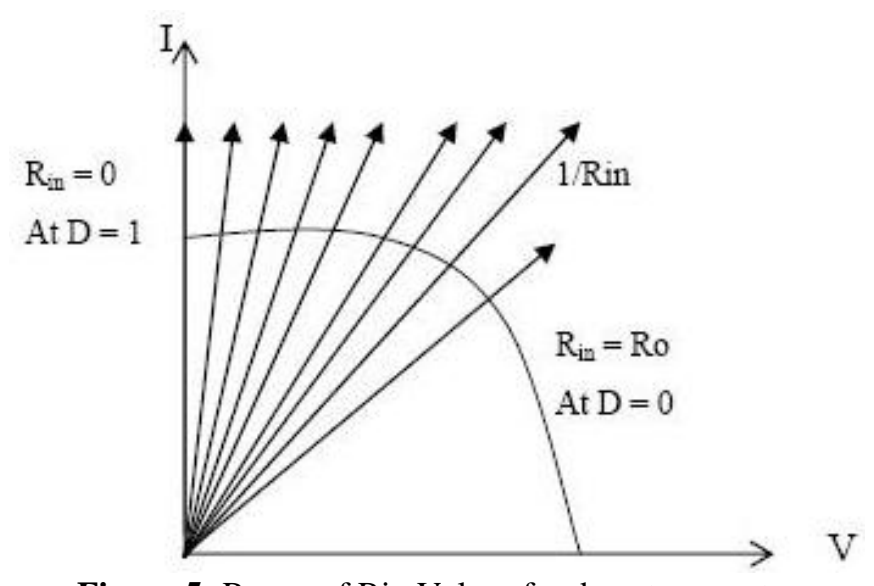

Figure 5: Range of Rin Values for boost converter

\subsection{Buck Boost Converter}

As the name indicates, this is a combination of buck converter and a boost converter. The circuit diagram is shown in the following figure

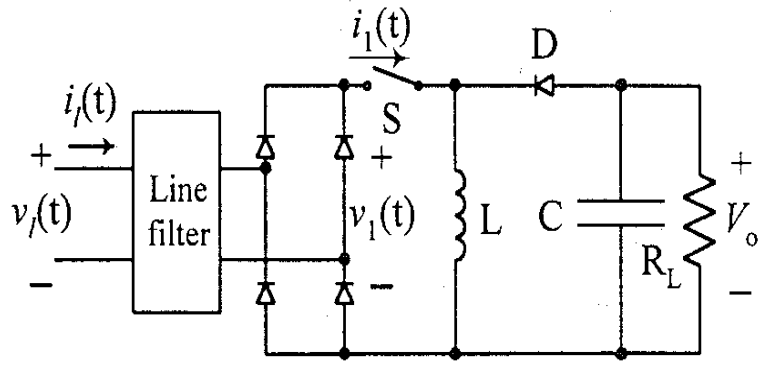

Figure 6: Buck boost converter

Here, the output voltage can be increased or decreased with respect to the input voltage by varying the duty cycle. This is clear from the conversion ratio given by the following expression:

$$
\frac{V_{o}}{V_{\text {in }}}=\frac{I_{\text {in }}}{I_{o}}=\frac{D}{1-D}
$$

Where D is the duty cycle. Knowing Vin and Iin, we can find the input resistance of the converter. This is given by

$$
R_{\text {in }}=\frac{R_{o} *(1-D)^{2}}{D^{2}}
$$

Here, Rin varies from $\infty$ to 0 as $D$ varies from 0 to 1 correspondingly. The range of Rin values for buck boost converters as shown in the following figures:

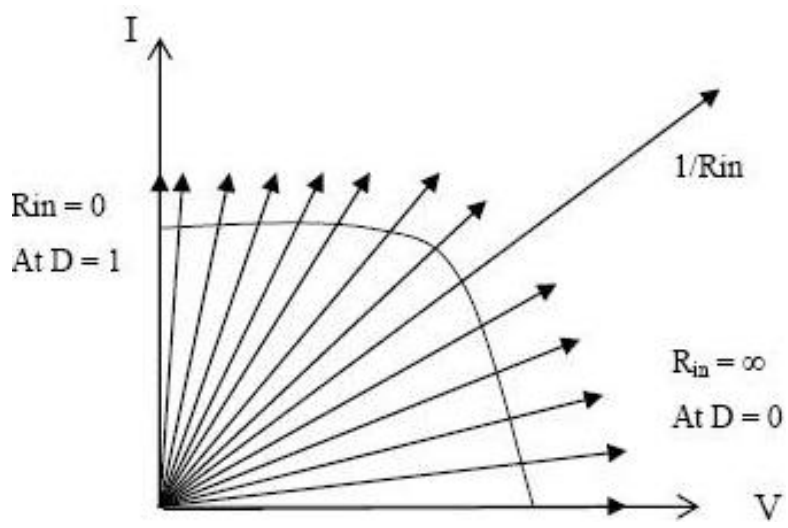

Figure 7: Range of Rin values for Buck-boost converter

\section{Boost Converter Design}

The boost converter design involves the selection of the inductor, the input and output capacitors. Necessary parameters required for the selection of these components are:

Input Voltage Range: Vin(min) and Vin(max)

Nominal output voltage: Vout $=\mathrm{Vdc}$

Maximum output current: Iout(max)

Selection of Boost Inductor: Once the minimum and maximum input voltage and output voltages are known the maximum and minimum duty cycles can be calculated as follows

$$
\begin{gathered}
D_{\text {max }}=\frac{\left(V_{\text {out }}-V i n_{\min }\right)}{V_{\text {out }}} \\
D_{\text {min }}=\frac{\left(V_{\text {out }}-V i n_{\max }\right)}{V_{\text {out }}}
\end{gathered}
$$

Where, Vout is nominal output voltage, Vin(max) is maximum input voltage, $\mathrm{Vin}(\mathrm{min})$ is minimum input voltage The average inductor current (maximum) can be calculated using the output current, Iout as follows:

$$
I l_{\text {avg }}=\frac{I_{\text {out }}}{1-D_{\max }}
$$

Assume the peak to peak inductor current ripple, delta IL, to be a certain percentage of the average inductor current calculated above. A good starting value of the inductor current ripple is assumed to be about 10 to $20 \%$ of the average output current. For a given switching frequency fs, the minimum inductor value required to remain in CCM can be calculated using the following equation

$$
L_{\min }=\frac{\operatorname{Vin}_{\min } * D_{\max }}{f_{s} *(\% \text { ripple }) * I_{L}}
$$

Selection of the Output Capacitor: In the boost converter, the instantaneous value of currents entering and exiting the output capacitor is very high. The value of capacitor is selected to limit the voltage ripple to a minimum value. Firstly the worst case duty ratio is calculated for maximum ripple in the output voltage which is usually the maximum duty cycle. And the following equation can be used to calculate the capacitor value for a desired voltage ripple

$$
\text { Cout }_{\min }=\frac{\text { Iout }_{\max } * D_{\max }}{f_{s} *(\% \text { ripple }) * V_{\text {out }}}
$$

Where, Cout(min) is minimum output capacitance, Iout(max) is maximum output current of the application, Dmax is maximum duty cycle calculated above, fs is minimum switching frequency of the converter, and Vout is desired output voltage ripple.

\section{Load parameters are}

Power Requirement $=36 \mathrm{~W}$, Current Requirement $=1.2 \mathrm{~A}$, Output Operating Voltage $=30 \mathrm{~V}$

This load can be a battery charging system or a simple Rload. 


\section{International Journal of Science and Research (IJSR) \\ ISSN (Online): 2319-7064}

Index Copernicus Value (2013): 6.14 | Impact Factor (2015): 6.391

\section{Converter parameters are}

Using above design equations we calculated minimum values of $\mathrm{L}$ and $\mathrm{C}$ for Continuous Conduction Mode of boost chopper $\mathrm{Lmin}=2 \mathrm{mH}, \mathrm{Cmin}=200 \mathrm{uF}, \mathrm{RL}=25 \mathrm{ohm}$

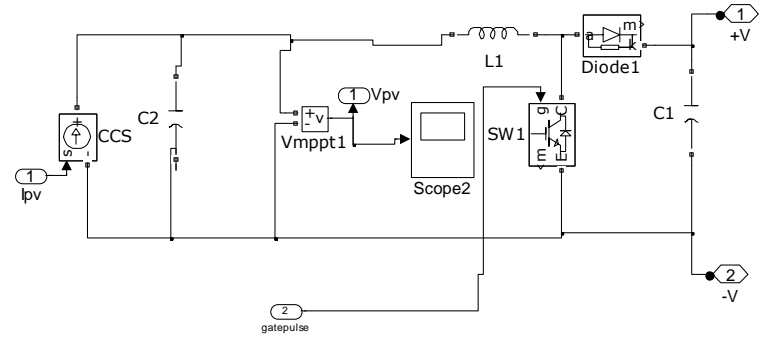

Figure 8: Boost Converter

\section{PV System}

Four parallel solar panels built by WARREE Energies Ltd. (WS-10) are used. The output of the Solar Panels is given as input to the boost converter. The table 6.2 gives rating of single module, we connect 2 such module in series and the combination is connected in parallel, to double the current and voltage ratings. A resistance of $250 \mathrm{ohm}$ is used as load. STM32F407VG microcontroller is used for the control circuit, with a sensing circuit interface for closed loop operation.

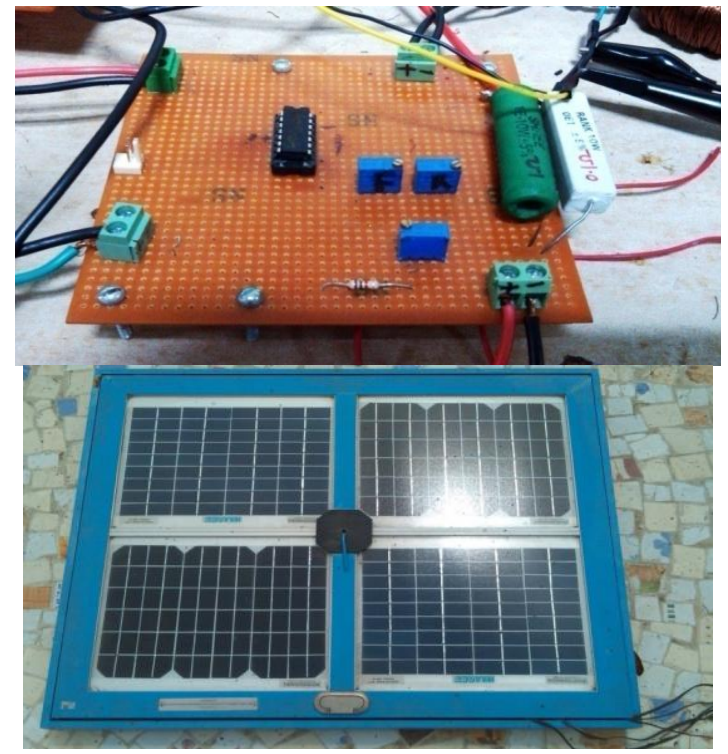

Figure 9: Solar Panel

Table 1: Solar Module Rating

\begin{tabular}{|c|c|}
\hline Solar Module Parameters & Rating \\
\hline Maximum Power & $10 \mathrm{~W}$ \\
\hline Voltage At maximum power & $17 \mathrm{~V}$ \\
\hline Current At Maximum power & $0.59 \mathrm{~A}$ \\
\hline Open Circuit Voltage & $21 \mathrm{~V}$ \\
\hline Short Circuit Current & $0.62 \mathrm{~A}$ \\
\hline
\end{tabular}

\section{Boost Chopper \& Sensing Circuit Interface}

The boost converter circuit and the sensing circuit are connected separately on different general purpose board. Connections for input supply, load, inductor, gate signals are given. Furthermore the sensing circuit gives out two quantities: the input voltage, and the input current. Now to sense the DC input current a series burden resistor of known value is used. Since the burden resistor needs to be of small value to not to affect the main circuit, the voltage drop across the resistor, is very small to be sensed by the ADC of the controller. An Op-Amp is used to amplify the voltage and then fed to the ADC of the controller. To adjust the voltages to $3.3 \mathrm{~V}$, to be fed to the controller, different preset resistors are used at several places. The circuit can be seen in fig.6.35. Table 2 shows the parameters used in design of the hardware prototype of boost converter using same equations used earlier in the design of the simulink model of boost converter

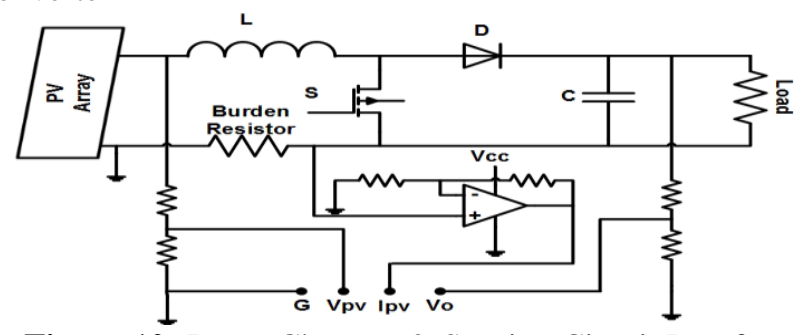

Figure 10: Boost Chopper \& Sensing Circuit Interface

Table 2: Converter Parameters

\begin{tabular}{|c|c|}
\hline Converter Parameters & Ratings \\
\hline Input voltage range & $0-40 \mathrm{~V}$ \\
\hline Switching Frequency $(f s)$ & $40 \mathrm{kHz}$ \\
\hline Inductance $(L)$ & $3 \mathrm{mH}$ \\
\hline Input Capacitance $(\mathrm{C} i)$ & $23.5 \mathrm{uF}$ \\
\hline Output Capacitance $(\mathrm{Co})$ & $40 \mathrm{Uf}$ \\
\hline Diode PIV & $90 \mathrm{~V}$ \\
\hline Maximum Power & $40 \mathrm{~W}$ \\
\hline
\end{tabular}

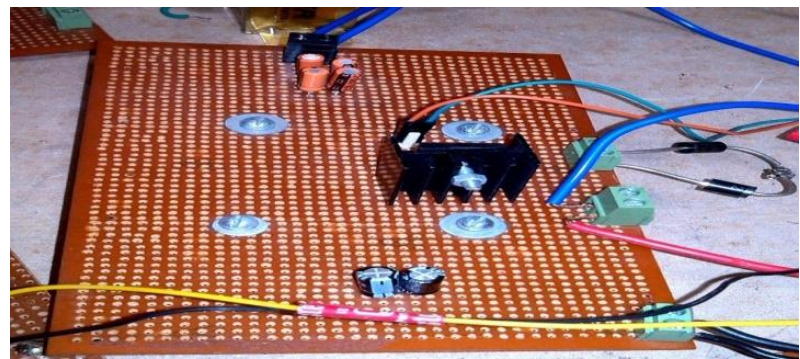

Figure 11: Hardware Prototype of Boost Chopper and Sensing Circuit

\section{Controller STM32F407VG}

The STM32F407VG discovery board and accompanying kit is used for the creation of PWM pulses, sensing of voltages and currents and interfacing with MATLAB for USART communication.

\section{Important features:}

- 3x12-bit, 2.4 MSPS A/D converters: up to 24 channels and 7.2 MSPS in triple interleaved mode however only 9channels are available on the kit.

- 2x12-bit D/A converters.

- Up to 17 timers: up to twelve 16-bit and two 32-bit timers up to $168 \mathrm{MHz}$, each with up to $4 \mathrm{IC} / \mathrm{OC} / \mathrm{PWM}$ or pulse counter.

- Core: ARM 32-bit Cortex-M4 CPU with FPU, Adaptive real-time accelerator (ART Accelerator) allowing 0-wait

\section{Volume 5 Issue 6, June 2016 www.ijsr.net}




\section{International Journal of Science and Research (IJSR) \\ ISSN (Online): 2319-7064}

Index Copernicus Value (2013): 6.14 | Impact Factor (2015): 6.391

state execution from Flash memory, frequency up to 168 MHz's. Peak throughput of 210 MIPS.

- Up to $140 \mathrm{I} / \mathrm{O}$ ports with interrupt capability.

- Up to 136 fast I/O up to 84 MHz's.

- Up to 1 Mbyte of flash memory.

- Up to 1385 V-tolerant I/Os.

- General purpose DMA, 16 stream DMA controller with FIFO and burst support. PWM timer features

- Maximum input clock is $168 \mathrm{MHz}$ to provide $5.95 \mathrm{~ns}$ edge resolution with the STM32 F4 series.

- No loss of resolution in centre-aligned mode.

- Uses an additional interrupt per PWM cycle or DMA transfers.

- Versatile PWM output management .Individually selectable polarities.

- Programmable hardware dead time generation.

ADC features:

- Single/dual/triple ADC with simultaneous conversion mode

- 12-bit resolution

- Down to $0.5 \mathrm{u}$ sec (F2 or F4 series) or 1u sec (F1 series) conversion time

- Up to 24 channels, plus internal temperature sensor and Vref

- Versatile channel sequencer

- DMA capable

- Programmable sampling rate

ADCs are used for sensing the grid voltages and the current following through the system. All three ADC are used in 'Triple Regular Simultaneous mode'. Only one Timer is used in the project which is programmed in output compare PWM mode which will compare the duty cycle function with the carrier wave to generate PWM pulses which are directly available on the port pins.DAC are used to visualize the reference and the other sensed signals.

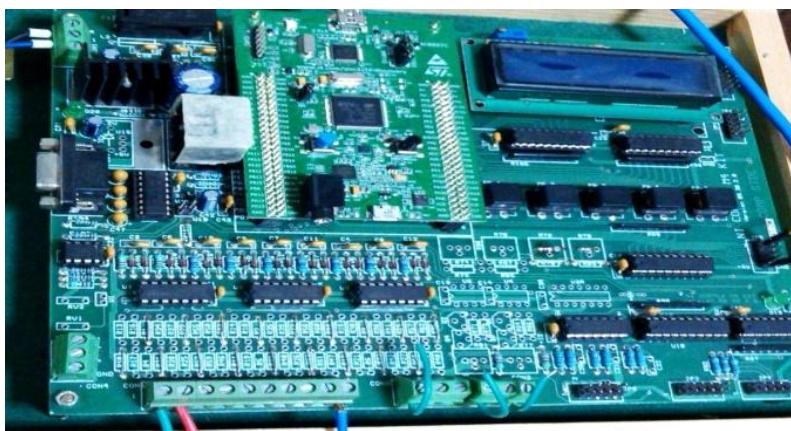

Figure 12: STM-32 Microcontroller Kit

\section{Gate Driver and Power Supply Circuit}

Power Supply-For regulated power supply ICs 7812 and 7912 are used for dual supply of $+/-12 \mathrm{~V}$.The input of $230 \mathrm{~V} / 15 \mathrm{~V}$ step down transformer is directly given to the rectifier input.The basic operational schematic is as shown in fig. 12 and IC connections are shown in fig. 13

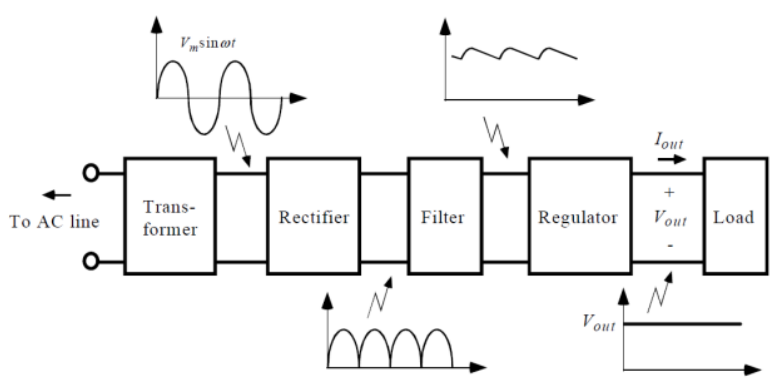

Figure 13: Complete schematic of linear power supply

Gate Driver -The Gate Driver circuit is used for firing the MOSFETs or IGBTs by getting inputs from a controller. The core for this circuit is the Gate Driver IC, TOSHIBA TLP250. It consists of a GaAlAs light-emitting diode and an integrated photo-detector. This unit is an 8-lead DIP package. The TLP250 is suitable for gate driving IGBTs or power MOSFETs. The switching time for the TLP250 is about $500 \mathrm{~ns}$ which makes it suitable for even frequencies of the order of $100 \mathrm{KHz}$.

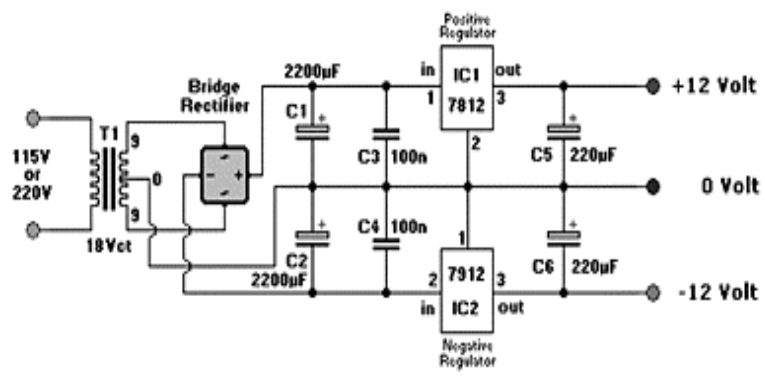

Figure 14: Circuit for dual power supply

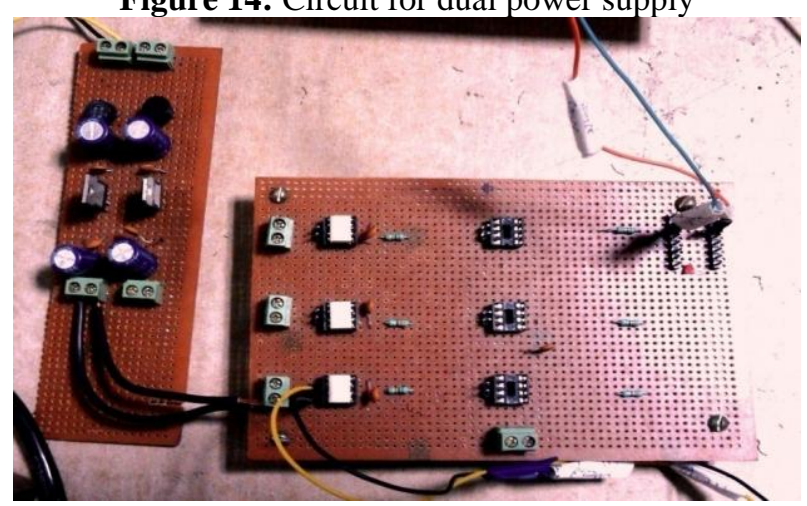

Figure 15: Hardware prototype of Regulated DC Supply And Gate Driver Circuits

\section{Complete Hardware Prototype Setup}

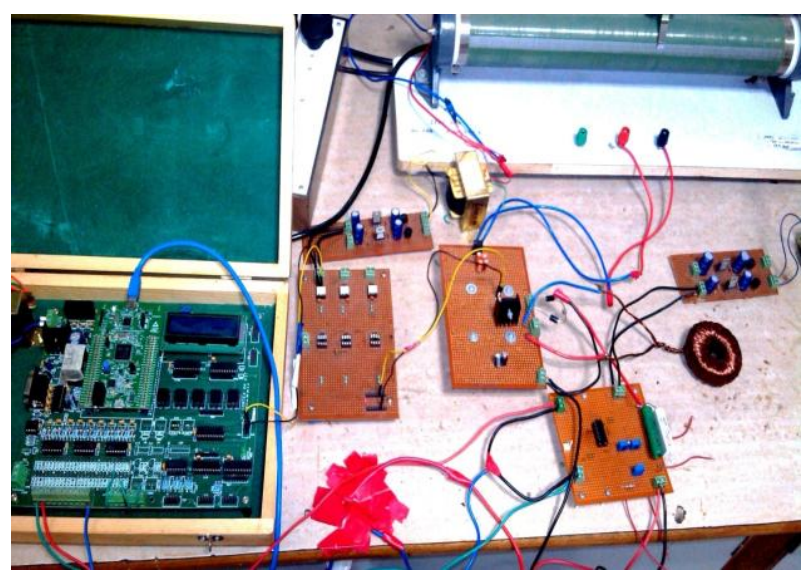

Figure 16: Complete Hardware Prototype Setup

Volume 5 Issue 6, June 2016 www.ijsr.net 


\section{International Journal of Science and Research (IJSR) \\ ISSN (Online): 2319-7064}

Index Copernicus Value (2013): 6.14 | Impact Factor (2015): 6.391

\section{Results and Observations}

First of all for the operation in open loop duty ratio and load resistance are fixed for maximum power point operation, by calculations from panel data sheet and boost chopper inputoutput relations. For further observations we can vary load resistance via rheostat to observe relations between panel current Ipv and panel voltage Vpv, which comes according to established relations.

$R_{M P P}=R_{\text {in }}$

$R_{\text {in }}=R_{o}(1-D)^{2}$

$V_{o}=V_{\text {in }} /(1-D)$

$R_{o}=28.8 /(1-0.56)^{2}=250 \mathrm{ohm}$

$V_{o}=28.8 /(1-0.56)=65 \mathrm{~V}$

Where $\mathrm{R}_{\mathrm{in}}=28.8$ is theoretical internal impedence.

The maximum power point panel impedance is calculated from panel data sheet, duty ratio is fixed at $\mathrm{D}=0.56$, for this case we calculate load, using above relations: The rheostat is set at $250 \mathrm{ohm}$ and STM-32 C code is set for 0.56 duty ratio. As per calculations panel voltage should operate at maximum power point, this is verified for different set of duty ratio of boost chopper and output rheostat value of resistance. As shown earlier the boost chopper when connected to a high resistance load will reduce the value of load resistance to match it with the maximum power point resistance value, i.e. it deliberately shifts the operating point from a point of high panel voltage and low panel current to a point of maximum panel voltage and close to short-circuit panel current. These theoretical results are verified using boost chopper operation in the open loop, where the duty ratio is preset and no further modifications can be made in it depending upon the varying conditions . The $\mathrm{C}$ code for this purpose is given in appendix A. The controller STM 32 gives a constant duty ratio gate pulses of $\mathrm{D}=0.56,40 \mathrm{kHz}$ as shown in below fig. 17.

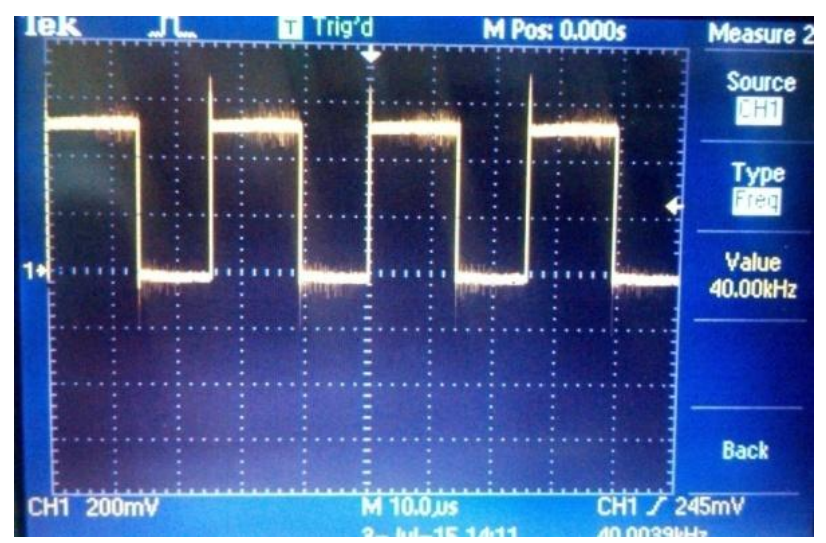

Figure 18: Gate Pulses of constant duty ratio

To observe the working of solar panel at different duty ratios, boost chopper duty cycle is varied in steps of 0.05 ,load resistance is kept constant at 200-ohm and following observations are made with variable gate pulses.
Table 3: Observation table for variable duty ratio boost chopper

\begin{tabular}{|c|c|c|c|c|c|}
\hline Sr.No. & Duty ratio(D) & $\mathrm{Vpv}(\mathrm{V})$ & $\operatorname{Vout}(\mathrm{V})$ & $\mathrm{Ipv}(\mathrm{A})$ & $\mathrm{Ppv}(\mathrm{W})$ \\
\hline 1 & 0.20 & 37.0 & 46.2 & 0.28 & 10.4 \\
\hline 2 & 0.25 & 36.4 & 48.0 & 0.32 & 11.6 \\
\hline 3 & 0.30 & 35.1 & 50.0 & 0.35 & 12.3 \\
\hline 4 & 0.35 & 34.0 & 52.3 & 0.40 & 13.6 \\
\hline 5 & 0.40 & 33.1 & 55.0 & 0.45 & 14.9 \\
\hline 6 & 0.45 & 32.7 & 58.1 & 0.52 & 17.0 \\
\hline 7 & 0.50 & 30.5 & 60.0 & 0.60 & 18.3 \\
\hline 8 & 0.55 & 29.0 & 64.4 & 0.71 & 20.6 \\
\hline 9 & 0.60 & 28.8 & 70.0 & 0.88 & 25.3 \\
\hline 10 & 0.65 & 27.2 & 77.1 & 0.82 & 22.3 \\
\hline 11 & 0.70 & 26.8 & 80.0 & 0.74 & 19.8 \\
\hline 12 & 0.75 & 25.5 & 85.0 & 0.67 & 17.1 \\
\hline 13 & 0.80 & 25.4 & 90.0 & 0.62 & 15.7 \\
\hline
\end{tabular}

The values of $\mathrm{Vpv}$ and Vout are measured from digital multimeter, whereas for getting current Ipv we divide voltage drop across burden resistor by its small value resistance. From table it is observed that as we begin from $\mathrm{D}=0.20$ upto $\mathrm{D}=0.60$ panel works to the right of MPP, while at $\mathrm{D}=0.60$ it operates at MPP and from $\mathrm{D}=0.65$ to $\mathrm{D}=0.80$ it operates to left of MPP.

\section{Conclusion}

The basic target has been to extract the maximum power from a stand-alone PV system for which we are using boost chopper in open and closed loop mode, for obtaining load impedance matching. In open loop mode we have preset the duty ratio of chopper and load resistance from theoretical calculations to observe maximum power point of module. In closed loop mode we sense panel current and voltage, compare them with preset values to obtain modified duty ratio so as to obtain load impedance matching. The complete arrangements including chopper topologies, gate driver circuits, sensing circuit, dc regulated supplies, STM 32 microcontroller kit, load rheostat are made. Sensing circuit and microcontroller are indispensable for this operation. Ccode for STM 32 microcontroller form the backbone in forming the MPPT system. After the theoretical analysis and its hardware implementation, we have reached a stage where we are sensing panel voltage and current, giving it to microcontroller and obtaining duty ratio using a basic algorithm. Furthermore, we can repeat same analysis for buck chopper or buck-boost chopper based MPPT. A buck chopper has been made in the laboratory, in case we select a different module and load.

\section{References}

[1] Hairul Nissah \& Saad Mekhilef, "Comparison Study of Maximum Power Point Tracker Techniques for PV Systems" Proceedings of the 14th International Middle East Power Systems Conference (MEPCON'10), Cairo University, Egypt, December 19-21, 2010.

[2] M.Lokanadham \& K.Vijaya Bhaskar," "Incremental Conductance Based Maximum Power Point Tracking (MPPT) for Photovoltaic System". International Journal of Engineering Research and Applications (IJERA) Vol. 2, Issue 2, Mar-Apr 2012. 


\section{International Journal of Science and Research (IJSR) \\ ISSN (Online): 2319-7064}

Index Copernicus Value (2013): 6.14 | Impact Factor (2015): 6.391

[3] N. Pandiarajan \& Ranganath Muthu, "Mathematical Modeling of Photovoltaic Module with Simulink" International Conference on Electrical Energy Systems (ICEES 2011), 3-5 Jan 2011.

[4] V.C. Kotak \& Preti Tyagi, "DC To DC Converter in Maximum Power Point Tracker". International Journal of Advanced Research in Electrical, Electronics and Instrumentation Engineering Vol. 2, Issue 12, Dec 2013.

[5] Soren Baekhoj Kjaer, "Evaluation of the "Hill Climbing" and the "Incremental Conductance" Maximum Power Point Trackers for Photovoltaic Power Systems". IEEE Transactions on Energy Conversion, Vol. 27, No. 4, December 2012.

[6] Rahul Rawat \& S. S. Chandel, "Hill Climbing Techniques for Tracking Maximum Power Point in Solar Photovoltaic Systems-A Review". Centre for Energy And Environment, National Institute Of Technology, Hamirpur, Himachal Pradesh-177005, India.

[7] Kinal Kachhiya, "The MATLAB/Simulink model of solar PV module and MPPT algorithm". National Conference on Recent Trends in Engineering \& Technology 13 \& 14 May 2011.

[8] Fan Zhang, Kary Thanapalan, Andrew Procter, Stephen Carr, and Jon Maddy "The Adaptive Hybrid Maximum Power Point Tracking Method for a Photovoltaic System". IEEE Transactions on Energy Conversion, Vol. 28, No. 2, June 2013.

Volume 5 Issue 6, June 2016 www.ijsr.net 